\title{
Initial stages of Gymnadenia conopsea (Orchidaceae) morphogenesis in in vitro culture
}

\author{
Alexandra Nabieva ${ }^{{ }^{*}}$, Elena Zhmud ${ }^{1}$, and Yulianna Zaytseva ${ }^{1}$ \\ ${ }^{1}$ Central Siberian botanical garden SB RAS, 630090 Zolotodolinskaya str. 101 Novosibirsk, Russia
}

\begin{abstract}
In the West Siberia there is very little data on the biology of cenopopulations of Gymnadenia conopsea. Habitat destruction and environmental changes, which potentially affected species long-term viability, led to G. conopsea cenopopulations fragmentation and isolation. A detailed study of the morphology variability of the Fragrant orchid representatives was carried out in the cenopopulation in Novosibirsk region. Our results indicate that asymbiotic germination of G. conopsea seeds is difficult to achieve and the species has serious conservation issues. It is the first report when the introduction of $G$. conopsea in tissue culture was undertaken as the initial stage of germplasm conservation of Siberian cenopopulation. Three modified nutrient media with different growth additives were tested to promote protocorm and seedling formation. The advanced G. conopsea seedlings establishment was obtained in $1 / 3$ Murashige and Skoog (MS) medium, supplemented by $1.0 \mathrm{mgl}^{-1} 2$ isopentenyladenine (2iP), $0.1 \mathrm{mgl}^{-1} 1$-Naphthaleneacetic acid (NAA) and $10 \%$ coconut water. This study allowed establishing a reliable and reproducible system for the G. conopsea maintenance and conservation ex situ.
\end{abstract}

\section{Introduction}

Gymnadenia conopsea (L.) R. Br. occurs all over Europe from Great Britain to the Mediterranean, eastwards to China and Japan [1]. Fragrant orchid (G. conopsea) is a polycarpic, perennial, terrestrial, glabrous herb [2]. G. conopsea assumed to be Least Concern species (LC), according to the IUCN Red List of Threatened Species (ver. 3.1). In Russia the number and size of G. conopsea cenopopulations (CP) have declined markedly during recent decades, mostly due to habitat destruction, agricultural intensification and overgrazing [3]. Despite that, many of the Fragrant orchid's CP are rural and protected by law in several regions of Russian Federation.

Vegetative propagation of the species is very limited; so that G. conopsea is heavily dependent on seed production [2], which is correlated with divergent mycorrhizal associations. Recently, investigators have begun studying and developing the methods for cultivating this plant, such as tissue culture, but this technology is still not applied widely.

* Corresponding author: sibflower05@gmail.com 
Propagation of orchids from seeds in nature as well as under in vitro conditions is a major bottleneck for the conservation of threatened taxa mainly from temperate zone [4]. G. conopsea seed germination and seedling establishment are strongly dependent on biotic and abiotic environmental conditions reflected by the presence of adult plants. Therefore, G. conopsea does not recover easily and presents conservation challenges: efficient efforts in studying new CP in Russia and, especially, in the Siberian region, are needed. In many cases, especially in temperate terrestrial orchids, higher germination rates have been achieved using green capsules rather than mature ones [5]. This phenomenon can be explained by the fact that in the immature seeds, scooped out from 'green' capsules at a certain time of fruit development, the ABA level is low and only a thin cuticle is observed around the embryo, while a thick seed coat and carapace have not yet fully developed.

The present investigations on G. conopsea were carried out with the objective to standardize conditions for asymbiotic germination of seeds and seedlings in green pod culture.

\section{Materials and methods}

G. conopsea was studied in 2019 under natural conditions in the Novosibirsk Region (NR), Russia. The cenopopulation is located at 190 m elevation; N 54027'42"; E 83020'42". Identification of species was done according to [6]. Morphometric analysis was applied for $15-20$ individuals in mature generative phase of development. The plants were randomly sampled across the whole CP.

Six replicates per capsule collected from the medium part of each specimen's inflorescence were washed under running tap water for $30 \mathrm{~min}$ and submerged in a mixture of 2 drops of Tween-20 and $20 \%$ 'Domestos' for $10 \mathrm{~min}$. Then capsules were treated with $0.25 \%$ mercuric chloride $(\mathrm{w} / \mathrm{v})$ for $8 \mathrm{~min}$ and then with $70 \%$ ethyl alcohol for $30 \mathrm{~s}$ and flamed. Finally, fruits were rinsed 3 times with sterilized distilled water. Seeds were cultured on three nutrient media: Knudson (Kn) [7], 1/3-strength MS [8] and Harvais (Har) [9]. For our experiments, we modified the media in similar way: agar was reduced from 10 to $6 \mathrm{~g} \mathrm{l}^{-1}$, sucrose from 30 to $10 \mathrm{~g} \mathrm{l}^{-1}$ and $10 \%$ coconut water $(\mathrm{CW})$ was added to all media (hereafter referred to as $\mathrm{mMS}$, mHar and $\mathrm{mKn}$ ). The $\mathrm{pH}$ was adjusted to 5.6 before autoclaving at $121^{\circ} \mathrm{C}$ for $15 \mathrm{~min}$. The cultures were maintained in darkness for $12 \mathrm{wk}$ and after the appearance of the first leaf they were placed under $16 \mathrm{~h}$ light and $8 \mathrm{~h}$ dark conditions at the non-changing temperature $\left(23 \pm 2^{\circ} \mathrm{C}\right)$. The germination rate (percentage of germinated seeds and protocorms at each developmental stage calculated by dividing the number of seeds which formed protocorms with promeristem among the total countered number of seeds) were assessed within $6,8,10,12 \mathrm{wk}$ after sowing. Germination indicated the emergence of the full embryo from the testa. For the induction of seed germination and protocorm development, all nutritious media were supplemented with $0.1 \mathrm{mgl}^{-1} \mathrm{NAA}$ and $1.0 \mathrm{mgl}^{-1} 2$-iP. The advanced seedling maintenance was achieved on $\mathrm{m} 1 / 3 \mathrm{MS}$ medium, in which $0.1 \mathrm{mgl}^{-1} \mathrm{NAA}$ and $1 \%$ activated charcoal (AC) were added. The duration of one passage was 2 months.

All experiments consisted of three independent replicates with six $150 \mathrm{ml}$ culture flasks, loaded with $30 \mathrm{ml}$ of the medium. Each flask contained approximately $100-150$ seeds.

\section{Results}

The local CP of G. conopsea studied has a small size (about 50 individuals with no less than 35 mature ones). So, a low proportion of immature plants was the characteristic mode in the CP. It occurred in open, wet grasslands as a part of well-lit partly flooded meadow at 
the edge of the birch forest. The projective cover of the whole herbage amounted to $80 \%$. We assessed morphological variation $(\mathrm{Cv}, \%)$ and it was revealed that all studied morphological traits of G. conopsea varied in the range which did not exceed $24 \%$

For the establishment of $G$. conopsea in vitro, the effects of medium composition and plant growth regulators (PGRs) concentrations on germination, protocorm formation and seedling growth were investigated through asymbiotic seed culture. Seeds germinated in a $24 \mathrm{~h}$ dark photoperiod for approximately $6-8 \mathrm{wk}$ in all 3 media studied, which have similar modifications by reducing agar to $6 \mathrm{~g} \mathrm{l}^{-1}$ and sucrose to $20 \mathrm{~g} \mathrm{l}^{-1}$ and supplementing with $10 \%$ coconut water. The seeds sown in August started to germinate after 6 wk (Fig. 1A, B).
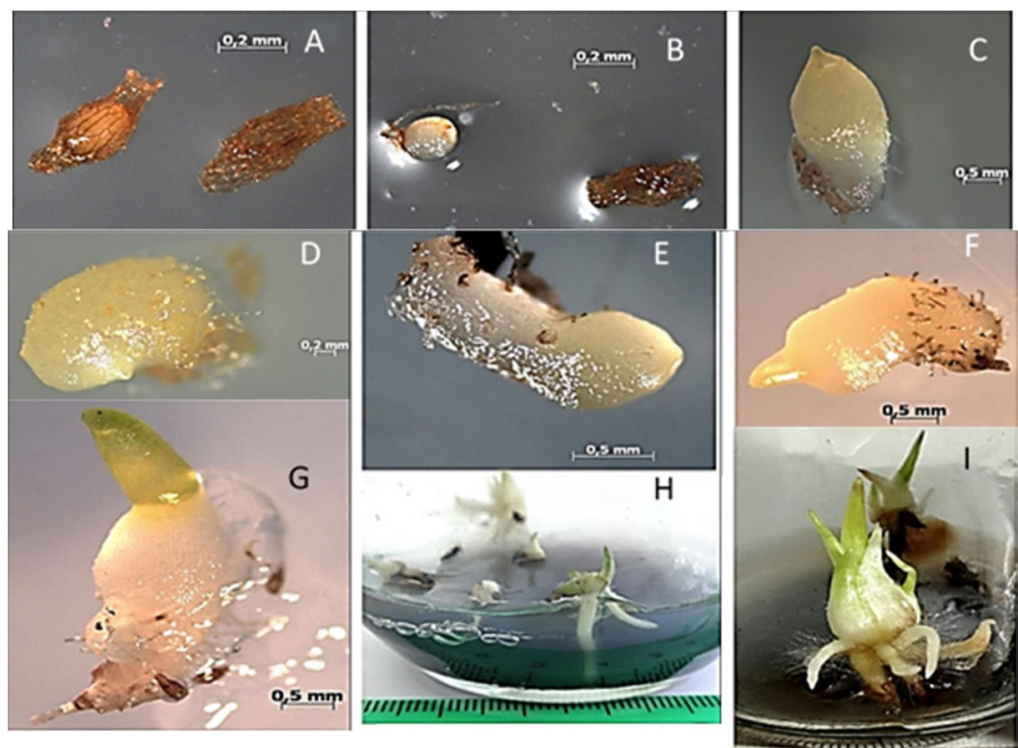

Fig. 1. The germination of immature seeds of Gymnadenia conopsea in vitro: A. Immature seeds; B. Embryo is completely discharged from the testa; C. Swelling embryo (=germination); D. Protocorm with 2 pointed shoot apexes; E. Absorbing hairs are formed on the protocorm-like body surface; F. Protocorm-like body: development of stem and young meristem; G. Seedling stage: the first leaf appearance; H. Seedlings with evident root emergence; I. Advanced seedling development with the formation of roots and leaves

The first protocorms (about $1.5 \mathrm{~mm}$ in diameter) with numerous rhizoids (Fig. 1C, D) appeared about $10 \mathrm{wk}$ after inoculation. During the development of the apical bud, the polarization and elongation of protocorms were observed (Fig. 1E). G. conopsea protocorms exhibited a phase of longitudinal growth and prolific rhizoid development (Fig. 1F) after emergence from the testa, when growth occurs at the chalazal pole, which was ordinarily shown for some other orchid species. After 12-wk period protocorm-like bodies (PLBs) developed from the protocorms with root- and shoot-primordia (Fig. 1F) were cultivated on the m1/3 MS medium with addition of $0.5 \mathrm{mgl}-1$ 2-iP mgl-1, $0.1 \mathrm{mgl}-1$ NAA and $1 \%$ AC.

Seedlings (Fig. 1G) were subcultured on m1/3 MS medium, supplemented with 0.5 $\mathrm{mgl}^{-1}$ 2-iP, $0.1 \mathrm{mgl}^{-1} \mathrm{NAA}$ and $1 \%$ AC. During the advanced developmental stage (Fig. $1 \mathrm{H})$ seedlings were maintained at $25^{\circ} \mathrm{C}$ in a $16 \mathrm{~h}$ photoperiod with a light intensity of 25 $\mu \mathrm{mol} \mathrm{m} \mathrm{m}^{-1}$.

Percentage of germinated seeds and protocorms at each developmental stage ranged from 4.25 to $17.28 \%$ among the replicates (Fig. 2). The mean germination per capsule was slightly higher after $10 \mathrm{wk}$ of incubation compared with that of seeds from the same site 
that had been incubated for 8 wk (Fig. 2). 1/3MS and Har media supplemented with $10 \%$ coconut water were the most suitable for G. conopsea seedling formation (Fig. 2). The highest germination rate and protocorm formation (Fig. 2) were obtained with $\mathrm{m} 1 / 3 \mathrm{MS}$ medium, supplemented with $0.3 \mathrm{mg} / \mathrm{l} \mathrm{NAA}, 1.0 \mathrm{mg} / 1$ 2-iP and $10 \% \mathrm{CW}$. Approximately 2.2 - cm tall sprouts of $G$. conopsea were obtained in vitro after 6 months (Fig. 1I).

\section{Discussion}

According to the data obtained, variation of morphometric characters of G. conopsea specimen in the CP studied was not high. Smaller average morphological parameters of individuals were recorded on the northern border of the range, in the Komi Republic (Russia) [10]. The local G. conopsea $\mathrm{CP}$ was characterized by high morphological identity of quantitative traits of individuals. The possibility of the existence of the species under various ecological-phytocenotic conditions in the Siberian region is based on the polymorphism of phenotypic manifestations of traits, which enhances the plasticity of G. conopsea. Thus, this orchid $\mathrm{CP}$ appears to be endangered due to the low intraspecific morphological variability.

In our experiment $G$. conopsea fully mature seeds couldn't germinate and this result is consistent with the data represented in [11], while the other authors [12] reported the increasing percentage germination of $G$. conopsea fully mature seeds to a maximum of $40 \%$ after $2 \mathrm{~h}$ of sterilization. We achieved propagation of $G$. conopsea through the use of near-mature capsules, which were green and non-dehisced. The low germination of G. conopsea seeds (17.28\%) (Fig. 2) under the experiment conditions may be the result of species inbreeding due to low number of the flowering plants in the local $\mathrm{CP}$, because spontaneous autogamy in G. conopsea was found to be accidental [13].

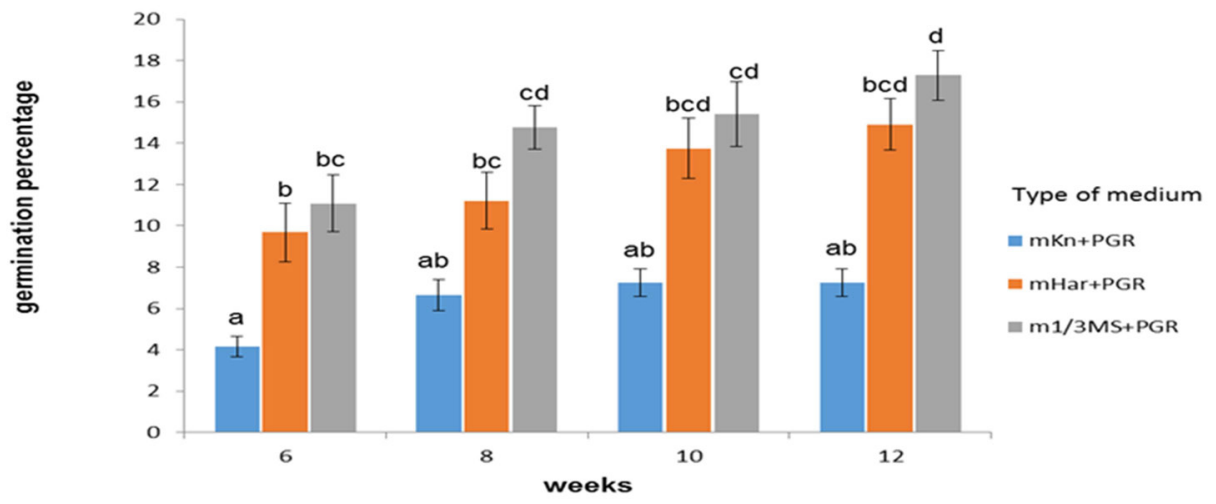

Fig. 2. Percentage of germination and protocorm formation by Gymnadenia conopsea seeds in asymbiotic culture on three different culture media with $10 \%$ coconut water and the identical set of plant growth regulators: 2-isopentenyladenine (2iP) and $0.1 \mathrm{mgl}-11$-naphthaleneacetic acid (NAA). Values in the column followed by different letters are significantly different $(p \leq 0.05)$ according to Duncan's test

But if it occurs, significant inbreeding depression manifesting in selfed seeds was revealed, e.g. in the CP of G. conopsea from the Czech Republic. This explanation may be suitable for the G. conopsea low germination rates obtained in our study, as well as in [11], where germination was also poor $(20 \%)$. Various studies reported that the traditional tissue culture media have been found to be too concentrated for temperate orchids, therefore, should be diluted approximately 2 to 10 times [14]. In our study, the $\mathrm{m} 1 / 3 \mathrm{MS}$ medium that 
worked well for seed germination was also successful in protocorms and seedlings formation and long culture maintenance. Different PGRs which induced protocorm-like bodies development (2-iP, thidiazuron (TDZ), 6-benzylaminopurine (BAP) and others) added alone or in combination with auxins were successfully used previously for other orchid species [15-17]. A combination of the high concentration of cytokinin (1.0 mgl-1 2iP) and low concentration of auxin ( $0.1 \mathrm{mgl}-1 \mathrm{NAA})$ applied in our study made a promoting effect on seed germination.

\section{Conclusions}

The studied G. conopsea CP was characterized by low morphological differentiation in terms of size and quantitative traits. The fact allowed us to concern the local $\mathrm{CP}$ in Novosibirsk region as endangered. The first stage of $G$. conopsea conservation strategy the introduction of the species in tissue culture was undertaken. The best medium for protocorm and seedling formation from $G$. conopsea immature seeds was $\mathrm{m} 1 / 3 \mathrm{MS}$, supplemented with $0.3 \mathrm{mg} / 1 \mathrm{NAA}, 1.0 \mathrm{mg} / 1$ 2-iP and $10 \% \mathrm{CW}$. In vitro asymbiotic seed germination of $G$. conopsea was successfully established and seedlings were obtained.

The work was carried out within the framework of the State Assignment for the Central Siberian Botanical Garden SB RAS No. AAAA-A17-117012610051-5 on the project "Assessment of the morphogenetic potential of plant populations in North Asia by experimental methods".

\section{References}

1. R. Soó, Orchis L. Flora Europaea, 5 (1980)

2. T. Meekers, M.J. Hutchings, O. Honnay, H. Jacquemyn, J. of Ecol. 100 (2012)

3. P.G. Efimov, Russian J. Genet. 49 (2013)

4. D.J. Merritt, F.R. Hay, N.D. Swarts, K.D. Sommerville, K.W. Dixon, Int. J. Plant Sci. 175 (2014)

5. J.P. Kendon, L. Rajaovelona, H. Sandford, R. Fang, J. Bell, V. Sarasan, Bot. stud, 58 (2017)

6. I.M. Krasnoborov, Determinant of plants of the Novosibirsk region, (2000)

7. L. Knudson, Amer. Orchid Soc. Bull, 15 (1946)

8. T. Murashige, F. Skoog, Physiol. Plant, 15 (1962)

9. G. Harvais, Can. J. Bot., 60 (1982)

10. I.A. Kirillova, D.V. Kirillov, Contemp. Probl. Ecol, 8 (2015)

11. L. Ding, L. Zhang, L. Guo, J. Sang, L.-X. Qin, B.-Q. Wang, Plant Physiol., 50 (2014)

12. J.M. Van Waes, P.C. Debergh, Physiol. Plant, 67 (1986)

13. I. Tałałaj, B. Ostrowiecka, E. Włostowska, A. Rutkowska, E. Brzosko, Acta Biol. Crac. Ser. Bot., 59 (2017)

14. G. Jakobsone, A. Osvalde, In Vitro Cell. Dev. Biol. Plant, 55 (2019)

15. P. Kauth, D. Dutra, T. Johnson, Advances and Topical Issues, (Global Science Books, London, 2008)

16. S. Zeng, Y. Zhang, J.A. Teixeira da Silva, K. Wu, J. Zhang, J. Duan, Crit. Rev. Biotechnol., 34 (2013)

17. K. Wotavová-Novotná, H. Vejsadová, P. Kindlmann, Biol. Plant, 51 (2007) 